\title{
GENERALISATIONS OF INTEGRAL INEQUALITIES OF HERMITE-HADAMARD TYPE THROUGH CONVEXITY
}

\author{
MUHAMMAD MUDDASSAR ${ }^{\bowtie}$, MUHAMMAD IQBAL BHATTI \\ and WAJEEHA IRSHAD
}

(Received 6 September 2012; accepted 10 October 2012; first published online 20 December 2012)

\begin{abstract}
In this paper, we establish various inequalities for some differentiable mappings that are linked with the illustrious Hermite-Hadamard integral inequality for mappings whose derivatives are $s-(\alpha, m)$-convex. The generalised integral inequalities contribute better estimates than some already presented. The inequalities are then applied to numerical integration and some special means.
\end{abstract}

2010 Mathematics subject classification: primary 26D10; secondary 26D15, 26A51.

Keywords and phrases: Hermite-Hadamard type inequality, $s-(\alpha, m)$-convex function, $p$-logarithmic mean, Hölder's integral inequality, trapezoidal formula, special means.

\section{Introduction}

Let $f: \emptyset \neq I \subseteq \mathbb{R} \rightarrow \mathbb{R}$ be a function defined on the interval $I$ of real numbers. Then $f$ is called convex if

$$
f(t x+(1-t) y) \leq t f(x)+(1-t) f(y)
$$

for all $x, y \in I$ and $t \in[0,1]$. Geometrically, this means that if $\mathrm{P}, \mathrm{Q}$ and $\mathrm{R}$ are three distinct points on the graph of $f$ with $\mathrm{Q}$ between $\mathrm{P}$ and $\mathrm{R}$, then $\mathrm{Q}$ is on or below the chord PR. There are many results associated with convex functions in the area of inequalities, one of these being the classical Hermite-Hadamard inequality:

$$
f\left(\frac{a+b}{2}\right) \leq \frac{1}{b-a} \int_{a}^{b} f(x) d x \leq \frac{f(a)+f(b)}{2}
$$

for $a, b \in I$, with $a<b$.

In [5], Hudzik and Maligranda considered, among others, the class of functions which are $s$-convex in the first and second sense. This class is defined as follows.

Definition 1.1. A function $f:[0, \infty) \rightarrow \mathbb{R}$ is said to be $s$-convex, or $f$ belongs to the class $K_{s}^{i}$, if

$$
f(\mu x+v y) \leq \mu^{s} f(x)+v^{s} f(y)
$$

holds for all $x, y \in[0, \infty), \mu, v \in[0,1]$ and for some fixed $s \in(0,1]$.

(C) 2012 Australian Mathematical Publishing Association Inc. 0004-9727/2012 \$16.00 
If $\mu^{s}+v^{s}=1$ the above class of convex functions is called $s$-convex in the first sense and represented by $K_{s}^{1}$; and if $\mu+v=1$ it is called $s$-convex in the second sense and represented by $K_{s}^{2}$. It may be noted that every 1 -convex function is convex.

In the same paper [5], Hudzik and Maligranda discussed a few results connected with $s$-convex functions in the second sense. Some new results on Hadamard's inequality for $s$-convex functions are discussed also in [4], as well as many important inequalities connected with 1-convex (convex) functions, one of which is (1.1).

In [10], Mihesan presented the class of $(\alpha, m)$-convex functions as reproduced below.

Definition 1.2. The function $f:[0, b] \rightarrow \mathbb{R}$ is said to be $(\alpha, m)$-convex, where $(\alpha, m) \in$ $[0,1]^{2}$, if, for every $x, y \in[0, b]$ and $t \in[0,1]$,

$$
f(t x+m(1-t) y) \leq t^{\alpha} f(x)+m\left(1-t^{\alpha}\right) f(y) .
$$

Note that for $(\alpha, m) \in\{(0,0),(\alpha, 0),(1,0),(1, m),(1,1),(\alpha, 1)\}$ one obtains the following classes of functions respectively: increasing, $\alpha$-star-shaped, star-shaped, $m$-convex, convex and $\alpha$-convex. For other new proofs, noteworthy extensions, generalisations and numerous applications on inequalities see [6-9, 12].

Denote by $K_{m}^{\alpha}(b)$ the set of all $(\alpha, m)$-convex functions on $[0, b]$ with $f(0) \leq 0$. For recent results and generalisations referring to $m$-convex and $(\alpha, m)$-convex functions, see $[1,2,13]$.

In [4], Dragomir and Pearce discussed inequalities for differentiable and twice differentiable functions connected with the Hermite-Hadamard inequality on the basis of the following lemma.

Lemma 1.3. Let $f: I \subseteq \mathbb{R} \rightarrow \mathbb{R}$ be a differentiable function on $I^{\circ}$ (the interior of $I$ ), $a, b \in I$ with $a<b$. If $f^{\prime} \in L^{1}[a, b]$, then

$$
\frac{f(a)+f(b)}{2}-\frac{1}{b-a} \int_{a}^{b} f(x) d x=\frac{(b-a)}{2} \int_{0}^{1}(1-2 t) f^{\prime}(t a+(1-t) b) d t .
$$

In [3], Dragomir and Agarwal established the following result connected with the right-hand side of (1.2) and applied it to some elementary inequalities for real numbers and numerical integration.

Lemma 1.4. Let $f: I^{\circ} \subseteq \mathbb{R} \rightarrow \mathbb{R}$ be a differentiable function on $I^{\circ}, a, b \in I$ with $a<b$. If $f^{\prime} \in L^{1}[a, b]$, then

$$
\begin{array}{r}
\frac{f(a)+f(b)}{2}-\frac{1}{b-a} \int_{a}^{b} f(x) d x=\frac{(b-a)}{2} \int_{0}^{1} \int_{0}^{1}\left(f^{\prime}(t a+(1-t) b)\right. \\
\left.-f^{\prime}(u a+(1-u) b)\right)(u-t) d t d u .
\end{array}
$$

This paper is organised as follows. In Section 2 we define a generalised convex function and discuss some new integral inequalities of Hermite-Hadamard type for generalised convex functions. In Section 3 we give some new applications for some special means. The inequalities are then applied to numerical integration in Section 4. 


\section{Definitions and main results}

To establish our principal results, we first give the following definitions.

Definition 2.1. A function $f:[0, \infty) \rightarrow[0, \infty)$ is said to be $s-(\alpha, m)$-convex in the first sense, or $f$ belongs to the class $K_{m, 1}^{\alpha, s}$, if for all $x, y \in[0, \infty)$ and $\mu \in[0,1]$, the following inequality holds:

$$
f(\mu x+(1-\mu) y) \leq\left(\mu^{\alpha s}\right) f(x)+m\left(1-\mu^{\alpha s}\right) f\left(\frac{y}{m}\right)
$$

where $(\alpha, m) \in[0,1]^{2}$ and for some fixed $s \in(0,1]$.

Definition 2.2. A function $f:[0, \infty) \rightarrow[0, \infty)$ is said to be $s$ - $(\alpha, m)$-convex in the second sense, or $f$ belongs to the class $K_{m, 2}^{\alpha, s}$, if for all $x, y \in[0, \infty)$ and $\mu, v \in[0,1]$, the following inequality holds:

$$
f(\mu x+(1-\mu) y) \leq\left(\mu^{\alpha}\right)^{s} f(x)+m\left(1-\mu^{\alpha}\right)^{s} f\left(\frac{y}{m}\right)
$$

where $(\alpha, m) \in[0,1]^{2}$ and for some fixed $s \in(0,1]$.

THEOREM 2.3. Let $f: I^{o} \subseteq \mathbb{R} \rightarrow \mathbb{R}$ be a differentiable function on $I^{o}$ (the interior of $I$ ), $a, b \in I$ with $a<b$, and $f^{\prime} \in L^{1}[a, b]$. If the mapping $\left|f^{\prime}\right|$ is $s$ - $(\alpha, m)$-convex on $[a, b]$, then

$$
\left|\frac{f(a)+f(b)}{2}-\frac{1}{b-a} \int_{a}^{b} f(x) d x\right| \leq \frac{b-a}{2}\left(v_{1}\left|f^{\prime}(a)\right|+v_{2}\left|f^{\prime}\left(\frac{b}{m}\right)\right|\right)
$$

where $v_{1}=\left(1+2^{\alpha s}(\alpha s)\right) / 2^{\alpha s}(\alpha s+1)(\alpha s+2)$ and $v_{2}=m\left(\frac{1}{2}-v_{1}\right)$.

Proof. From Lemma 1.3,

$$
\left|\frac{f(a)+f(b)}{2}-\frac{1}{b-a} \int_{a}^{b} f(x) d x\right| \leq \frac{b-a}{2} \int_{0}^{1}|1-2 t|\left|f^{\prime}(t a+(1-t) b)\right| d t .
$$

Since $\left|f^{\prime}\right|$ is $s-(\alpha, m)$-convex on $[a, b]$ for all $t \in[0,1]$, this becomes

$$
\begin{aligned}
& \left|\frac{f(a)+f(b)}{2}-\frac{1}{b-a} \int_{a}^{b} f(x) d x\right| \\
& \quad \leq \frac{b-a}{2} \int_{0}^{1}|1-2 t|\left(t^{\alpha s}\left|f^{\prime}(a)\right|+m\left(1-t^{\alpha s}\right)\left|f^{\prime}\left(\frac{b}{m}\right)\right|\right) d t .
\end{aligned}
$$

Here

$$
\int_{0}^{1} t^{\alpha s}|1-2 t| d t=\int_{0}^{1 / 2}(1-2 t) t^{\alpha s} d t+\int_{1 / 2}^{1}(2 t-1) t^{\alpha s} d t=\frac{1+2^{\alpha s}(\alpha s)}{2^{\alpha s}(\alpha s+1)(\alpha s+2)}
$$

and

$$
\int_{0}^{1}\left(1-t^{\alpha s}\right)|1-2 t| d t=\frac{1}{2}-\frac{1+2^{\alpha s}(\alpha s)}{2^{\alpha s}(\alpha s+1)(\alpha s+2)} .
$$

Inequalities (2.3), (2.4) and (2.5) together imply (2.1). 
Remark 2.4. For $(\alpha, m)=(1,1)$ in $(2.1)$, we get [11, Theorem 2].

THeOREM 2.5. Let the assumptions of Theorem 2.3 be satisfied with $p>1$, such that $q=p /(p-1)$. If the mapping $\left|f^{\prime}\right|^{q}$ is $s-(\alpha, m)$-convex on $[a, b]$, then

$$
\left|\frac{f(a)+f(b)}{2}-\frac{1}{b-a} \int_{a}^{b} f(x) d x\right| \leq \frac{b-a}{2(p+1)^{1 / p}}\left(\frac{\left|f^{\prime}(a)\right|^{q}+m \alpha s\left|f^{\prime}\left(\frac{b}{m}\right)\right|^{q}}{\alpha s+1}\right)^{1 / q} .
$$

Proof. By applying Hölder's inequality to the right-hand side of (2.2),

$$
\int_{0}^{1}\left|1-2 t \| f^{\prime}(t a+(1-t) b)\right| d t \leq\left(\int_{0}^{1}|1-2 t|^{p} d t\right)^{1 / p}\left(\int_{0}^{1}\left|f^{\prime}(t a+(1-t) b)\right|^{q} d t\right)^{1 / q} .
$$

Here,

$$
\int_{0}^{1}|1-2 t|^{p} d t=\frac{1}{1+p}
$$

Since $\left|f^{\prime}\right|^{q}$ is $s-(\alpha, m)$-convex on $[a, b]$ for all $t \in[0,1]$,

$$
\left|f^{\prime}(t a+(1-t) b)\right|^{q} \leq t^{\alpha s}\left|f^{\prime}(a)\right|^{q}+m\left(1-t^{\alpha s}\right)\left|f^{\prime}(b)\right|^{q},
$$

so the second integral on the right-hand side of (2.7) can be simplified by simple integration as:

$$
\int_{0}^{1}\left|f^{\prime}(t a+(1-t) b)\right|^{q} d t=\frac{\left|f^{\prime}(a)\right|^{q}+m \alpha s\left|f^{\prime}\left(\frac{b}{m}\right)\right|^{q}}{\alpha s+1} .
$$

Inequalities (2.7), (2.8) and (2.9) together imply (2.6).

Remark 2.6. For $(\alpha, m)=(1,1)$ in $(2.6)$, we get [11, Theorem 4].

THeOREM 2.7. Let the assumptions of Theorem 2.3 be satisfied with $q>1$. If the mapping $\left|f^{\prime}\right|^{q}$ is $s-(\alpha, m)$-convex on $[a, b]$, then

$$
\left|\frac{f(a)+f(b)}{2}-\frac{1}{b-a} \int_{a}^{b} f(x) d x\right| \leq \frac{b-a}{2^{(p+1) / p}}\left(v_{1}\left|f^{\prime}(a)\right|^{q}+v_{2}\left|f^{\prime}\left(\frac{b}{m}\right)\right|^{q}\right)^{1 / q}
$$

where $v_{1}=\left(1+2^{\alpha s}(\alpha s)\right) / 2^{\alpha s}(\alpha s+1)(\alpha s+2)$ and $v_{2}=m\left(\frac{1}{2}-v_{1}\right)$.

Proof. Inequality (2.2) reduces to the following form:

$$
\begin{aligned}
& \left|\frac{f(a)+f(b)}{2}-\frac{1}{b-a} \int_{a}^{b} f(x) d x\right| \\
& \quad \leq \frac{b-a}{2} \int_{0}^{1}|1-2 t|^{1 / p}|1-2 t|^{1 / q}\left|f^{\prime}(t a+(1-t) b)\right| d t
\end{aligned}
$$

where $1 / p+1 / q=1$. 
By applying Hölder's inequality to (2.11), for $q>1$,

$$
\begin{aligned}
& \left|\frac{f(a)+f(b)}{2}-\frac{1}{b-a} \int_{a}^{b} f(x) d x\right| \\
& \quad \leq \frac{b-a}{2}\left(\int_{0}^{1}|1-2 t| d t\right)^{1 / p}\left(\int_{0}^{1}|1-2 t|\left|f^{\prime}(t a+(1-t) b)\right|^{q} d t\right)^{1 / q} .
\end{aligned}
$$

Applying the $s$ - $(\alpha, m)$-convexity of $\left|f^{\prime}\right|^{q}$ on $[a, b]$ for all $t \in[0,1]$ to the second integral on the right-hand side of (2.12),

$$
\begin{aligned}
& \left|\frac{f(a)+f(b)}{2}-\frac{1}{b-a} \int_{a}^{b} f(x) d x\right| \\
& \quad \leq \frac{b-a}{2}\left(\frac{1}{2}\right)^{1 / p}\left(t^{\alpha s}|1-2 t|\left|f^{\prime}(a)\right|^{q}+m\left(1-t^{\alpha s}\right)|1-2 t|\left|f^{\prime}\left(\frac{b}{m}\right)\right|^{q} d t\right)^{1 / q} .
\end{aligned}
$$

Here,

$$
\int_{0}^{1} t^{\alpha s}|1-2 t| d t=\frac{1+2^{\alpha s}(\alpha s)}{2^{\alpha s}(\alpha s+1)(\alpha s+2)}
$$

and, similarly,

$$
\int_{0}^{1}\left(1-t^{\alpha s}\right)|1-2 t| d t=\frac{1}{2}-\frac{1+2^{\alpha s}(\alpha s)}{2^{\alpha s}(\alpha s+1)(\alpha s+2)} .
$$

Inequalities (2.13), (2.14) and (2.15) together imply (2.10).

Remark 2.8. For $(\alpha, m)=(1,1)$ in $(2.10)$, we get [11, Theorem 6].

TheOREM 2.9. Let $f: I^{o} \subseteq \mathbb{R} \rightarrow \mathbb{R}$ be a differentiable function on $I^{o}$ (the interior of $I$ ), $a, b \in I$ with $a<b$, and $f^{\prime} \in L^{1}[a, b]$. If the mapping $\left|f^{\prime}\right|$ is $s-(\alpha, m)$-convex on $[a, b]$, then

$$
\left|\frac{f(a)+f(b)}{2}-\frac{1}{b-a} \int_{a}^{b} f(x) d x\right| \leq \frac{(b-a)}{2}\left(u_{1}\left|f^{\prime}(a)\right|+u_{2}\left|f^{\prime}\left(\frac{b}{m}\right)\right|\right),
$$

where $u_{1}=\left((\alpha s)^{2}+3 \alpha s+4\right) / 2(\alpha s+1)(\alpha s+2)(\alpha s+3)$ and $u_{2}=m\left(\frac{1}{3}-u_{1}\right)$.

Proof. Taking absolute values in (1.3),

$$
\begin{aligned}
& \left|\frac{f(a)+f(b)}{2}-\frac{1}{b-a} \int_{a}^{b} f(x) d x\right| \\
& \quad \leq \frac{b-a}{2} \int_{0}^{1} \int_{0}^{1}\left|f^{\prime}(t a+(1-t) b)-f^{\prime}(u a+(1-u) b) \| u-t\right| d t d u \\
& \quad=(b-a) \int_{0}^{1} \int_{0}^{1}\left|f^{\prime}(t a+(1-t) b) \| u-t\right| d t d u .
\end{aligned}
$$


Since $\left|f^{\prime}\right|$ is $s-(\alpha, m)$-convex on $[a, b]$ for all $t \in[0,1],(2.17)$ may be written as

$$
\begin{aligned}
& \left|\frac{f(a)+f(b)}{2}-\frac{1}{b-a} \int_{a}^{b} f(x) d x\right| \\
& \quad \leq(b-a) \int_{0}^{1} \int_{0}^{1}\left(t^{\alpha s}|u-t|\left|f^{\prime}(a)\right|+m\left(1-t^{\alpha s}\right)|u-t|\left|f^{\prime}\left(\frac{b}{m}\right)\right|\right) d t d u .
\end{aligned}
$$

Here,

$$
\begin{aligned}
\int_{0}^{1} \int_{0}^{1} t^{\alpha s}|u-t| d t d u & =\int_{0}^{1}\left(\int_{0}^{u} t^{\alpha s}(u-t) d t+\int_{u}^{1} t^{\alpha s}(t-u) d t\right) d u \\
& =\frac{(\alpha s)^{2}+3 \alpha s+4}{2(\alpha s+1)(\alpha s+2)(\alpha s+3)}
\end{aligned}
$$

and, analogously,

$$
\int_{0}^{1} \int_{0}^{1}\left(1-t^{\alpha s}\right)|u-t| d t d u=\frac{1}{3}-\frac{(\alpha s)^{2}+3 \alpha s+4}{2(\alpha s+1)(\alpha s+2)(\alpha s+3)} .
$$

Inequalities (2.18), (2.19) and (2.20) together imply (2.16).

Remark 2.10. For $(\alpha, m)=(1,1)$ in $(2.16)$, we get [11, Theorem 8].

THeOREM 2.11. Let the assumptions of Theorem 2.9 be satisfied with $p>1$, such that $q=p /(p-1)$. If the mapping $\left|f^{\prime}\right|^{q}$ is $s-(\alpha, m)$-convex on $[a, b]$, then

$$
\begin{aligned}
& \left|\frac{f(a)+f(b)}{2}-\frac{1}{b-a} \int_{a}^{b} f(x) d x\right| \\
& \quad \leq(b-a)\left(\frac{2}{(p+1)(p+2)}\right)^{1 / p}\left(\frac{\left|f^{\prime}(a)\right|^{q}+m \alpha s\left|f^{\prime}\left(\frac{b}{m}\right)\right|^{q}}{\alpha s+1}\right)^{1 / q} .
\end{aligned}
$$

Proof. By applying Hölder's inequality to the right-hand side of (2.2),

$$
\begin{aligned}
& \left|\frac{f(a)+f(b)}{2}-\frac{1}{b-a} \int_{a}^{b} f(x) d x\right| \\
& \leq(b-a)\left(\int_{0}^{1} \int_{0}^{1}\left|f^{\prime}(t a+(1-t) b)\right|^{q} d t d u\right)^{1 / q} \\
& \quad \times\left(\int_{0}^{1} \int_{0}^{1}|u-t|^{p} d t d u\right)^{1 / p} .
\end{aligned}
$$

Here,

$$
\int_{0}^{1} \int_{0}^{1}|u-t|^{p} d t d u=\frac{2}{(p+1)(p+2)}
$$


By the $s$ - $(\alpha, m)$-convexity of $\left|f^{\prime}\right|^{q}$ on $[a, b]$ for all $t \in[0,1]$, the first integral on the right-hand side of (2.22) may be solved as

$$
\int_{0}^{1} \int_{0}^{1}\left|f^{\prime}(t a+(1-t) b)\right|^{q} d t d u \leq \frac{\left|f^{\prime}(a)\right|+m \alpha s\left|f^{\prime}\left(\frac{b}{m}\right)\right|}{\alpha s+1} .
$$

Inequalities (2.22), (2.23) and (2.24) together imply (2.21).

Remark 2.12. For $(\alpha, m)=(1,1)$ in $(2.21)$, we get [11, Theorem 10].

TheOREM 2.13. Let the assumptions of Theorem 2.9 be satisfied with $q>1$. If the mapping $\left|f^{\prime}\right|^{q}$ is $s-(\alpha, m)$-convex on $[a, b]$, then

$$
\left|\frac{f(a)+f(b)}{2}-\frac{1}{b-a} \int_{a}^{b} f(x) d x\right| \leq \frac{b-a}{3^{1 / p}}\left(u_{1}\left|f^{\prime}(a)\right|^{q}+u_{2}\left|f^{\prime}\left(\frac{b}{m}\right)\right|^{q}\right)^{1 / q},
$$

where $u_{1}=\left((\alpha s)^{2}+3 \alpha s+4\right) / 2(\alpha s+1)(\alpha s+2)(\alpha s+3)$ and $u_{2}=m\left(\frac{1}{3}-u_{1}\right)$.

Proof. By applying Hölder's inequality to the right-hand side of (2.2),

$$
\begin{aligned}
& \left|\frac{f(a)+f(b)}{2}-\frac{1}{b-a} \int_{a}^{b} f(x) d x\right| \\
& \leq(b-a)\left(\int_{0}^{1} \int_{0}^{1}|u-t|\left|f^{\prime}(t a+(1-t) b)\right|^{q} d t d u\right)^{1 / q} \\
& \quad \times\left(\int_{0}^{1} \int_{0}^{1}|u-t| d t d u\right)^{1 / p} .
\end{aligned}
$$

Here,

$$
\int_{0}^{1} \int_{0}^{1}|u-t| d t d u=\frac{1}{3}
$$

By the $s$ - $(\alpha, m)$-convexity of $\left|f^{\prime}\right|^{q}$ on $[a, b]$ for all $t \in[0,1]$, the first integral on the right-hand side of (2.26) may be estimated as

$$
\begin{aligned}
\int_{0}^{1} & \int_{0}^{1}|u-t|\left|f^{\prime}(t a+(1-t) b)\right|^{q} d t d u \\
\quad \leq & \int_{0}^{1} \int_{0}^{1}|u-t|\left(t^{\alpha s}\left|f^{\prime}(a)\right|^{q}+m\left(1-t^{\alpha s}\right)\left|f^{\prime}\left(\frac{b}{m}\right)\right|^{q}\right) d t d u,
\end{aligned}
$$

and

$$
\int_{0}^{1} \int_{0}^{1} t^{\alpha s}|u-t| d t d u=\frac{\alpha s^{2}+3 \alpha s+4}{2(\alpha s+1)(\alpha s+2)(\alpha s+3)}
$$

and

$$
\int_{0}^{1} \int_{0}^{1}\left(1-t^{\alpha s}|u-t| d t d u=\frac{1}{3}-\frac{\alpha s^{2}+3 \alpha s+4}{2(\alpha s+1)(\alpha s+2)(\alpha s+3)},\right.
$$

which completes the proof.

Remark 2.14. For $(\alpha, m)=(1,1)$ in $(2.25)$, we get [11, Theorem 12]. 


\section{Application to some special means}

Let us recall the following means for any two positive numbers $a$ and $b$ :

(1) the arithmetic mean,

$$
A \equiv A(a, b)=\frac{a+b}{2} ;
$$

(2) the geometric mean,

$$
G \equiv G(a, b)=\sqrt{a b}
$$

(3) the harmonic mean,

$$
H \equiv H(a, b)=\frac{2 a b}{a+b}
$$

(4) the p-logarithmic mean,

$$
L_{p} \equiv L_{p}(a, b)= \begin{cases}a & \text { if } a=b, \\ \left(\frac{b^{p+1}-a^{p+1}}{(p+1)(b-a)}\right)^{1 / p} & \text { if } a \neq b ;\end{cases}
$$

(5) the identric mean,

$$
I \equiv I(a, b)= \begin{cases}a & \text { if } a=b, \\ \frac{1}{e}\left(\frac{b^{b}}{a^{a}}\right)^{1 /(b-a)} & \text { if } a \neq b ;\end{cases}
$$

(6) the logarithmic mean,

$$
L \equiv L(a, b)= \begin{cases}a & \text { if } a=b, \\ \frac{b-a}{\log b-\log a} & \text { if } a \neq b .\end{cases}
$$

The following inequalities are well known in the literature (see [14]):

$$
H \leq G \leq L \leq I \leq A .
$$

It is also known that $L_{p}$ is monotonically increasing over $p \in \mathbb{R}$, denoting $L_{0}=I$ and $L_{-1}=L$.

Proposition 3.1. Let $p>1,0<a<b$ and $q=p /(p-1)$. Then

$$
|A(a, b)-L(a, b)| \leq \frac{\log b-\log a}{2(p+1)^{1 / p}} A^{1 / q}\left(|a|^{q},|b|^{q}\right) .
$$

Proof. By Theorem 2.5 applied to the mapping $f(x)=e^{x}$ for $(\alpha, m)=(1,1)$, we have (3.1).

Proposition 3.2. Let $p>1,0<a<b$ and $q=p /(p-1)$. Then

$$
\left|\frac{I(a, b)}{G(a, b)}\right| \leq \exp \left(\frac{b-a}{2} H^{-1 / q}\left(|a|^{q},|b|^{q}\right)\right) .
$$


Proof. The result follows by Theorem 2.7 , setting $f(x)=-\log (1-x)$ for $(\alpha, m)=$ $(1,1)$.

Another result connected with the $p$-logarithmic mean $L_{p}(a, b)$ is the following proposition.

Proposition 3.3. Let $p>1,0<a<b$ and $q=p /(p-1)$. Then

$$
\left|A\left(a^{n}, b^{n}\right)-L_{n}^{n}\left(a^{n}, b^{n}\right)\right| \leq|n|^{q} \frac{b-a}{3} A\left(|a|^{q(n-1)},|b|^{q(n-1)}\right) .
$$

Proof. The result follows by Theorem 2.13, setting $f(x)=(1-x)^{n},|n| \geq 2$ and $n \in \mathbb{Z}$ for $(\alpha, m)=(1,1)$.

\section{Error estimates for the trapezoidal formula}

Let $D$ be the partition $\left\{a=x_{0}<x_{1}<\cdots<x_{n-1}<x_{n}=b\right\}$ of the interval $[a, b]$ and consider the quadrature formula

$$
\int_{a}^{b} f(x) d x=S(f, D)+R(f, D)
$$

where

$$
S(f, D)=\sum_{k=0}^{n-1} \frac{f\left(x_{k}\right)+f\left(x_{k+1}\right)}{2}\left(x_{k+1}-x_{k}\right)
$$

for the trapezoidal version and $R(f, D)$ denotes the related approximation error.

Proposition 4.1. Let $f: I \subseteq \mathbb{R} \rightarrow \mathbb{R}$ be a differentiable mapping on $I^{o}$ such that $f^{\prime} \in$ $L^{1}[a, b]$, where $a, b \in I$ with $a<b$ and $\left|f^{\prime}\right|$ is s-convex on $[a, b]$. For every partition $D$ of $[a, b]$ the trapezoidal error approximation satisfies

$$
|R(f, D)| \leq \frac{1}{2^{1 / p}}\left(\frac{s \cdot 2^{s}+1}{2^{s}(s+1)(s+2)}\right)^{1 / q} \sum_{k=0}^{n-1} \frac{\left(x_{k+1}-x_{k}\right)^{2}}{2}\left(\left|f^{\prime}\left(x_{k}\right)\right|+\left|f^{\prime}\left(x_{k+1}\right)\right|\right),
$$

where $p>1$.

Proof. By applying Theorem 2.7 on the subinterval $\left[x_{k}, x_{k+1}\right]$ of the partition $D$ of $[a, b]$ for $k=0,1,2, \ldots, n-1$, for $(\alpha, m)=(1,1)$ and using the fact that $\sum_{m=1}^{n-1}\left(\Phi_{m}+\right.$ $\left.\Psi_{m}\right)^{r} \leq \sum_{m=1}^{n-1}\left(\Phi_{m}\right)^{r}+\sum_{m=1}^{n-1}\left(\Psi_{m}\right)^{r}$ for $0<r<1$, where for each $m$ both $\Phi_{m}, \Psi_{m} \geq 0$,

$$
\begin{aligned}
& \left|f\left(\frac{x_{k+1}+x_{k}}{2}\right)-\frac{1}{x_{k+1}-x_{k}} \int_{x_{k}}^{x_{k+1}} f(x) d x\right| \\
& \quad \leq \frac{x_{k+1}-x_{k}}{2^{(p+1) / p}}\left(\frac{s \cdot 2^{s}+1}{2^{s}(s+1)(s+2)}\right)^{1 / q}\left(\left|f^{\prime}\left(x_{k}\right)\right|+\left|f^{\prime}\left(x_{k+1}\right)\right|\right) .
\end{aligned}
$$


Taking the sum over $k$ from 0 to $n-1$ and taking into account that $\left|f^{\prime}\right|^{q}$ is $s$ - $(\alpha, m)$ convex,

$$
\begin{aligned}
\left|\int_{a}^{b} f(x) d x-S(f, K)\right| & =\left|\sum_{k=0}^{n-1}\left(\int_{x_{k}}^{x_{k+1}} f(x) d x-\left(x_{k+1}-x_{k}\right) \frac{f\left(x_{k+1}\right)+f\left(x_{k}\right)}{2}\right)\right| \\
& \leq \sum_{k=0}^{n-1}\left|\left(\int_{x_{k}}^{x_{k+1}} f(x) d x-\left(x_{k+1}-x_{k}\right) \frac{f\left(x_{k+1}\right)+f\left(x_{k}\right)}{2}\right)\right| .
\end{aligned}
$$

This gives

$$
|R(f, D)| \leq \sum_{k=0}^{n-1}\left(x_{k+1}-x_{k}\right)\left|\frac{f\left(x_{k+1}\right)+f\left(x_{k}\right)}{2}-\frac{1}{x_{k+1}-x_{k}} \int_{x_{k}}^{x_{k+1}} f(x) d x\right| .
$$

By combining (4.2) and (4.3), we get (4.1), which completes the proof.

Proposition 4.2. Let $f: I \subseteq \mathbb{R} \rightarrow \mathbb{R}$ be a differentiable mapping on $I^{o}$ such that $f^{\prime} \in$ $L^{1}[a, b]$, where $a, b \in I$ with $a<b$ and $\left|f^{\prime}\right|^{q}$ is $s$ - $(\alpha, m)$-convex on $[a, b]$. Then for every partition $D$ of $[a, b]$ the trapezoidal error approximation satisfies

$$
\begin{aligned}
|R(f, D)| & \leq\left(\frac{2}{3}\right)^{1 / p}\left(\frac{s^{2}+3 s+4}{(s+1)(s+2)(s+3)}\right)^{1 / q} \sum_{k=0}^{n-1} \frac{\left(x_{k+1}-x_{k}\right)^{2}}{2}\left(\left|f^{\prime}\left(x_{k}\right)\right|^{q}+\left|f^{\prime}\left(x_{k+1}\right)\right|^{q}\right)^{1 / q} \\
& \leq\left(\frac{2}{3}\right)^{1 / p}\left(\frac{s^{2}+3 s+4}{(s+1)(s+2)(s+3)}\right)^{1 / q} \sum_{k=0}^{n-1} \frac{\left(x_{k+1}-x_{k}\right)^{2}}{2}\left(\left|f^{\prime}\left(x_{k}\right)\right|+\left|f^{\prime}\left(x_{k+1}\right)\right|\right) .
\end{aligned}
$$

Proof. The proof is very similar to that of Proposition 4.1, using Theorem 2.13.

\section{Acknowledgements}

This research paper has been made possible through the help and support of Professor A. D. Raza Choudary (Director General, ASSMS, Lahore) and Professor Muhammad Ozair Ahmed (Chairperson, Department of Mathematics, University of Engineering and Technology, Lahore), and we thank them for their support and encouragement. We also gratefully acknowledge the time and expertise devoted to reviewing papers by the advisory editors, the members of the editorial board, and the referees.

\section{References}

[1] M. K. Bakula, M. E. Özdemir and J. Pečarić, 'Hadamard type inequalities for $m$-convex and $(\alpha, m)$ convex functions', J. Inequal. Pure and Appl. Math. 9 (2008), Article 96.

[2] M. K. Bakula, J. Pečarić and M. Ribičić, 'Companion inequalities to Jensen's inequality for $m$ convex and $(\alpha, m)$-convex functions', J. Inequal. Pure and Appl. Math. 7 (2006), Article 194.

[3] S. S. Dragomir and R. P. Agarwal, 'Two inequalities for differentable mappings and applications to special means of real numbers and to trapezoidal formula', Appl. Math. Lett. 11(5) (1998), 91-95. 
[4] S. S. Dragomir and C. E. M. Pearce, Selected Topics on Hermite-Hadamard Inequalities and Applications. RGMIA Monographs Victoria University 2000.

(http://ajmaa.org/RGMIA/monographs.php/).

[5] H. Hudzik and L. Maligrada, 'Some remarks on s-convex functions', Aequationes Math. 48 (1994), $100-111$.

[6] S. Hussain, M. I. Bhatti and M. Iqbal, 'Hadamard-type inequalities for $s$-convex functions I', Punjab Univ. J. Math. 41 (2009), 51-60.

[7] H. Kavurmaci, M. Avci and M. E. Özdemir, 'New inequalities of Hermite-Hadamard type for convex functions with applications', J. Inequal. Appl. (2011), Article 86.

[8] U. S. Kirmaci, 'Inequalities for differentiable mappings and applications to special means of real numbers and to mid point formula', Appl. Math. Comp. 147 (2004), 137-146.

[9] U. S. Kirmaci and M. E. Özdemir, 'On some inequalities for differentiable mappings and applications to special means of real numbers and to midpoint formula', Appl. Math. Comput. 153 (2004), 361-368.

[10] V. G. Mihesan, 'A generalization of the convexity', Seminar on Functional Equations, Approx. and Convex., Cluj-Napoca (Romania) (1993).

[11] M. Muddassar, M. I. Bhatti and M. Iqbal, 'Some new $s$-Hermite Hadamard type ineqalities for differentiable functions and their applications', Proc. Pakistan Acad. Sci. 49(1) (2012), 9-17.

[12] C. E. M. Pearce and J. Pečarić, 'Inequalities for differentable mappings with application to special means and quadrature formulae', Appl. Math. Lett. 13(2) (2000), 51-55.

[13] E. Set, M. Sardari, M. E. Özdemir and J. Rooin, 'On generalizations of the Hadamard inequality for $(\alpha, m)$-convex functions', RGMIA Res. Rep. Coll. 12(4) (2009), Article 4.

[14] M. Z. Sarikaya, E. Set and M. E. Özdemir, New Inequalities of Hermite-Hadamard's Type, Research Report Collection, Vol 12, Issue 4, 2009.

(http://ajmaa.org/RGMIA/papers/v12n4/set2.pdf).

MUHAMMAD MUDDASSAR, Department of Mathematics, University of Engineering and Technology, Lahore, Pakistan

e-mail: malik.muddassar@gmail.com

MUHAMMAD IQBAL BHATTI, Department of Mathematics, University of Engineering and Technology, Lahore, Pakistan e-mail: uetzone@hotmail.com

WAJEEHA IRSHAD, Department of Mathematics, University of Engineering and Technology, Lahore, Pakistan e-mail:wchattah@hotmail.com 